\title{
PENDIDIKAN KEWARGANEGARAAN; IKHTIAR MENCEGAH KONFLIK DAN MEMBINA TOLERANSI
}

\author{
Dahlan Lama Bawa ${ }^{1}$ \\ ${ }^{* 1}$ Pendidikan Agama Islam Fakultas Agama Islam| Unismuh Makassar
}

\begin{abstract}
ABSTRAK
Tulisan mengenai Pendidikan Kewarganegaraan; ikhtiar mencegah konflik dan membina toleransi ini dilatarbelakangi oleh adanya konflik atas nama agama yang pernah terjadi di Indonesia pada kurun waktu tahun 1990-2000-an. Tujuan penulisan ini dimaksudkan untuk menanamkan nilai-nilai demokrasi dan toleransi kepada masyarakat Indonesia pada umumnya dan mahasiswa khususnya yang memprogramkan mata kuliah Civic Education. Metode penelitian yang digunakan untuk menggali informasi pada tulisan ini adalah deskriptif-kualitatif, dengan pendekatan fenomenologis. Adapun sumber data terdiri dua sumber data yaitu sumber data primer dan sekunder. Sumber data primer, yakni penulis menggali informasi dari data-data mengenai konflik atas nama agama di Indoensia baik dalam bentuk buku-buku ilmiah maupun jurnal laporan hasil penelitian. Sedangkan sumber data sekunder, yakni penulis menghimpun data dan informasi di media cetak dan elektronik. Adapun intrumen dalam penelitian ini adalah penulis sendiri sebagai instumen kunci. Adapun temuan hasil penelitian ini menunjukkan bahwa pemicu konflik atas anama agama di Indonesia terdiri dari tiga faktor, yakni faktor adanya pelecehan/penodaan agama, adanya sikap yang mau menang sendiri serta mengabaikan kehadiran umat beragama lain, adanya diskomunikasi dan miskomunikasi antar umat beragama.
\end{abstract}

\section{Kata kunci: Penanaman Nilai-nilai Demokrasi dan Toleransi}

\begin{abstract}
Written of civic education; the effort to prevent and maintain tolerance is based by there were conflicts was the name of religion that occurred in Indonesia in the period 1990-2000's. The purpose of this research is intended to build the values of democracy and tolerance to the society generally and students particulary who program Civic Education subject. Research method used to find information in this paper is descriptivequalitative, with phenomenological approach. The data sources consist of two data sources are primary and secondary. Primary data sources, are the researcher find information from data about the conflict in the name of religion in Indonesia both scientific books and report research journals. While secondary data sources, are the researcher collect data and information in print and electronic media. Instrument of this research is the researcher himself as a key. The findings of this research indicate that the trigger of conflict religion in Indonesia consists of three factors, namely the factors religious desecration, the attitude of self-defeating and the disregard presence of other religious communities, the existence of discommunication and miscommunication among religious people.
\end{abstract}

\section{Keywords: Build Democratic Values and Tolerance}


PENDAHULUAN

Bangsa Indonesia dikenal sebagai bangsa yang religius, memiliki dinamika dan dialektika dalam kehidupan bernegara di atas pilar Pancasila, UUD 45, NKRI dan Bhineka Tunggal Ika. Komitmen terhadap empat pilar tersebut merupakan ikhtiar mewujudkan suasana damai dan harmonis, namun dalam kenyataannya, pada kurun waktu tahun 1990-2000an, Indonesia berada dalam suasana kelam kehidupan umat beragama, ditandai dengan adanya konflik Ambon, Poso, Sambas, Kupang, dan Situbondo. Di sinilah pentingnya pendidikan kewarganeagaan sebagai ikhtiar mencegah konflik dan disintegrasi bangsa.

\section{METODE PENELITIAN}

Metode yang digunakan dalam penelitian ini adalah metode deskriptif kualitatif. Penelitian deskriptif merupakan penelitian yang bertujuan menggambarkan suatu kondisi atau fenomena pendidik tidak memilahmilah atau mencari faktor-faktor atau variabel tertentu.
Penelitian kualitatif tidak mengenal istilah populasi melainkan menggunakan istilah "situasi sosial" (social situation) yang memiliki tiga elemen, yaitu tempat (place), pelaku (actors), serta aktivitas (activity) yang berinteraksi secara sinergis dan tidak dapat dipisahkan (Sugiyono, 2009). Teknik yang digunakan dalam penelitian ini, yaitu:

\section{Studi Kepustakaan}

Pengumpulan data pertama-tama dilakukan melalui pengkajian literatur untuk mengungkapkan teori-teori yang relevan dengan topik penelitian

\section{Wawancara}

Wawancara yang dimaksud adalah Wawancara dengan model percakapan kedua belah pihak. Dalam konteks penelitian ini, peneliti merupakan pewawancara dengan mewawancarai para pihak yang dianggap memiliki keterkaitan dengan penelitian ini, yakni; Pemerintah, tokoh masyarakat, masyarakat biasa.

\section{HASIL DAN PEMBAHASAN \\ PENELITIAN}




\section{Konflik Atas Nama Agama}

Menurut Mustari Mustafa, konflik atas nama agama di Indonesia, dapat dijumpai dalam berbagai kasus, misalnya penyerbuan oleh massa anti Ahmadiyah, gerakan Front Pembela Islam (FPI), pemboikotan aliran-aliran sempalan, aksi-aksi untuk solidaritas Palestina, aksi-aksi anti-Barat, Yahudi, dan Amerika atas dasar sikap dan kebijakan negara-negara tersebut, serta kasus kecurigaan antara kelompokkelompok penganut agama.

Munculnya kasus terkait dengan persoalan keagamaan, umumnya dipicu oleh beberapa hal antar lain, 1) Pelecehan/penodaan agama melalui penggunaan simbolsimbol, maupun istilah-istilah keagamaan dari suatu agama oleh pihak lain secara tidak bertanggung jawab, 2) Fanatisme agama. Fanatisme yang dimaksud adalah suatu sikap yang mau menang sendiri serta mengabaikan kehadiran umat beragama lain yang memiliki cara/ritual ibadah dan paham agama yang berbeda, 3) Adanya diskomunikasi dan miskomunikasi antar umat beragama. Konflik ini dapat terjadi karena adanya miskomunikasi (salah paham) dan diskomunikasi (komunikasi yang buruk)

Sehubungan dengan penodaan agama di Indonesia, pernah terjadi kasus penistaan agama oleh Gubernur DKI Jakarta, Basuki Tjahaya Purnama (Ahok), saat melakukan kunjungan kerja terkait budi daya ikan kerapu di Pulau Pramuka Kepualuan Seribu, tanggal, 27 September 2016. Dalam pidatonya di hadapan ribuan warga, beliau menyinggung surah al-Maidah ayat 51 dengan mengatakan bahwa "Kan dalam hati kecil Bapak Ibu, ngga pilih saya karena dibohongi (orang) pakai surah al-Maidah 51 macammacam itu".

Pidato Ahok tersebut direkam dan disebarluaskan videonya ke media sosial oleh seorang warga Jakarta bernama Bunyani. Tersebarnya video tersebut, menimbulkan reaksi umat Islam begitu besar, hal ini ditunjukkan dengan gelombang aksi besar-besaran untuk menyampaikan aspirasi, jutaan umat Islam hadir di Istiqlal dan Istana Negara tanggal, 4 Novembr 2016 dengan tuntutan menghukum Ahok karena menista agama, yang dikenal dengan aksi 411, namun karena Ahok 
sudah dijadikan tersangka tetapi belum ditangkap, maka aksi jutaan umat Islam berlanjut di Monas dan jalanjalan protokol di Jakarta pada tanggal, 2 Desember 2016, yang dikenal dengan aksi 212. Aksi ini berlangsung super damai dan memecahkan rekor dunia karena untuk pertama kalinya terjadi di dunia di luar Kota Mekkah, shalat jum'at dihadiri jutaan jama'ah, diantara jama'ah yang hadir adalah Presiden RI, Joko Widodo, Wapres, Jusuf Kalla, Mentri Polhukam, Wiranto, Ketua MUI dan sejumlah ulama dan habaib. Menyusul aksi yang digelar oleh ribuan umat Islam, tanggal, 13 Maret 2017, yang dikenal dengan aksi damai 313, star dari Masjid Istiqlal menuju Istana Presiden RI. Melalui proses persidangan yang terbuka dan transparan, akhirnya hakim memutuskan Ahok bersalah karena menodai agama dan dihukum penjara 2 tahun oleh Majelis Hakim Pengadilan Negeri Jakarta Utara pada tanggal, 9 Mei 2017.

Kasus Ahok tersebut, menimbulkan aroma ketegangan berlatar agama dan membuat sulit untuk disangkal bahwa persatuan, bahkan keutuhan Negara Kesatuan
Repubik Indonesia (NKRI) berada dalam bahaya disintegrasi bangsa. Ancaman runtuhnya NKRI juga datang dari dua kecenderungan, pertama, merebaknya konflik-konflik komunalistik yang pernah terjadi di negeri ini, kedua, gerakan dalam masyarakat di beberapa proponsi yang menjadi perhatian pemerintah dan TNI, seperti Gerakan Aceh Merdeka (GAM), Organisasi Papua Merdeka (OPM), Republik Maluku Selatan (RMS) yang sewaktu-waktu bisa menuntut diadakannya referendum tentang apakah mereka tetap berada dalam Negara Kesatuan Republik Indonesia (NKRI) atau mau mandiri. Dalam kondisi seperti ini, tidak ada pilihan lain kecuali belajar untuk hidup bersama dalam suasana pluralistik, untuk itu diperlukan kebersamaan dalam membangun masyarakat yang terbuka. Dan sebaliknya, kita tidak akan memecahkan masalah-masalah itu dengan menyerah kepada komunalisme.

Konflik itu ibarat kanker ganas yang sewaktu-waktu dapat merusak sistem imunitas tubuh serta jaringan saraf, sehingga harus senantiasa menjaga dan merawat imunitas tubuh 
agar tetap sehat. Dengan demikian, maka bagi bangsa Indonesia, harus selalu melakukan pemetaan potensi konflik dan ancaman kerukunan hidup antar umat beragama di Indonesia berdasarkan Suku, Agama dan Ras (SARA) yang tersebar dari Sabang sampai Merauke, mengingat Indonesia memiliki potensi konflik berbasis keagamaan primordial etnik, sosial politik, dan sosial ekonomi. Oleh karena itu, perlu dilakukan studi yang sifatnya spesifik dan mendalam. Di samping itu, pemerintah Indonesia harus senantiasa memperhatikan pembangunan bidang ekonomi dan pengadaan infrastruktur di seluruh penjuru tanah air, wilayah perbatasan dengan negara-negara tetangga, khususnya pembangunan di Kawasan Timur Indonesia (KTI), serta menggali akar budaya yang tumbuh dan berkembang di tengah masyarakat secara akademik.

\section{Civic Education \& Toleransi}

Urgensi pendidikan kewargenegaraan (civic eduaction) di Indonesia meliputi penanaman nilainilai kewargaan (cicic value) di dalamnya terkandung upaya sosialisasi, desiminasi, dan aktualisasi konsep, sistem, serta nilai-nilai demokrasi, nilai-nilai keadilan, persaudaraan, keterbukaan, persamaan hak dan kewajiban, partisipatif warga, etos kerja, toleransi, pluralisme, anti korupsi dan supremasi hukum. Dari sekian pokok kajian civic education tersebut, hal yang perlu mendapat perhatian adalah toleransi (tasamuh) Hal ini penting, mengingat Indonesia terdiri dari berbagai Suku, Agama dan Ras (SARA) yang tentu sangat rawan konflik.

Oleh karena itu, diperlukan proposisi untuk membina toleransi (tasamuh) sebagai alternatif konseptual, sekaligus sebagai landasan yang kokoh bagi kehidupan masyarakat tanpa konflik atas nama agama, uraian proposisi sebagai berikut:

a) Sebagai masyarakat muslim yang baik kita meyakini bahwa setiap manusia dari sudut pandang penciptaannya (ontologis) memiliki kemuliaan (karamah), apapun ras, warna kulit, suku, bangsa termasuk agamanya, sesuai dengan firman Allah dalam QS.al-Isra'/17: 70 


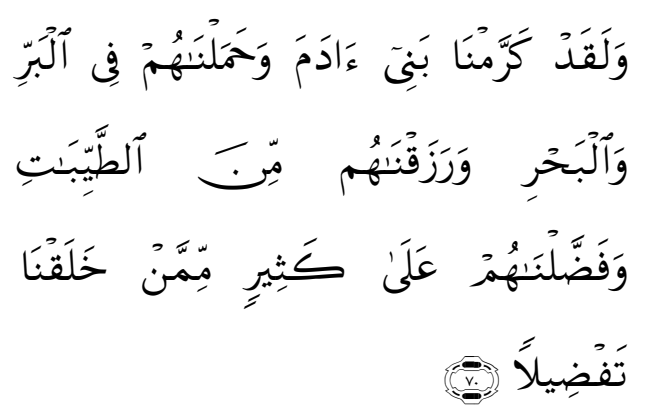

Terjemahnya:

Dan sesungguhnya telah Kami muliakan anak-anak Adam, Kami angkut mereka di daratan dan di lautan, Kami beri mereka rezki dari yang baikbaik dan Kami lebihkan mereka dengan kelebihan yang sempurna atas kebanyakan makhluk yang telah Kami ciptakan (al-Isra'/17:70)

b) Bersikap apresiatif terhadap fakta keragaman dan berlapang dada, karena perbedaan keyakinan dan agama merupakan sesuatu yang qodrati dari Allah swt.

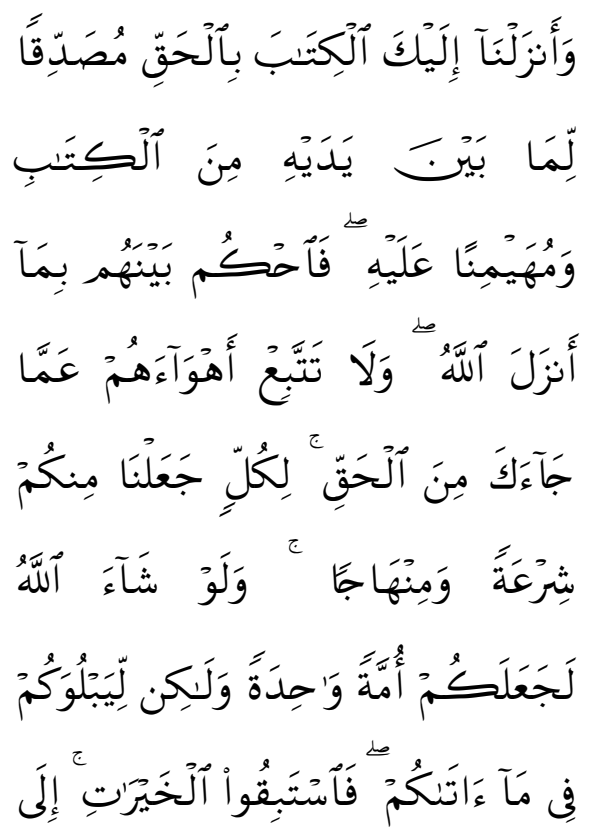

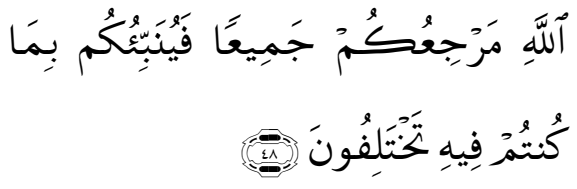

Terjemahnya:

Dan Kami telah turunkan kepadamu Al-Qur'an dengan membawa kebenaran, membenarkan apa yang sebelumnya, yaitu kitab-kitab (yang diturunkan sebelumnya) dan batu ujian terhadap kitabkitab yang lain itu; maka putuskanlah perkara mereka menurut apa yang Allah turunkan dan janganlah kamu mengikuti hawa nafsu mereka dengan meninggalkan kebenaran yang telah datang kepadamu. Untuk tiap-tiap umat diantara kamu, kami berikan aturan dan jalan yang terang. Sekiranya Allah menghendaki, niscaya kamu dijadikan-Nya satu umat (saja), tetapi Allah hendak menguji kamu terhadap pemberian-Nya kepadamu, maka berlombalombalah berbuat kebajikan. Hanya kepada Allah-lah kamu kembali semuanya, lalu diberitahukan-Nya kepadamu apa yang telah kamu perselisihkan itu (Qs.alMa'idah/5:48)

c) Memahami bahwa perintah dakwah dalam Islam bertujuan terwujudnya transformasi dan perubahan kepada kebaikan dan kebenaran, disertai sebuah pemahaman bahwa, Allah swt. 
tidak membebani kita untuk bertanggung jawab atas kekufuran orang-orang kafir atau kesesatan orang-orang yang sesat. Masalah terpenting ialah, dakwah telah kita sampaikan, sebagaimana firman Allah swt.

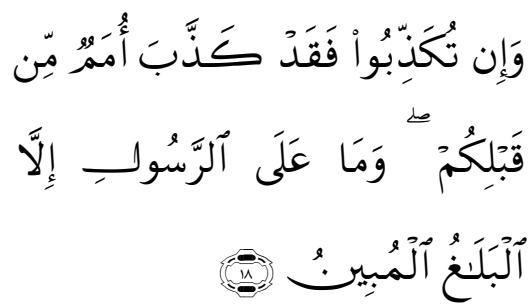

Terjemahnya:

Dan jika kamu (orang kafir) mendustakan, maka umat yang sebelum kamu juga telah mendustakan. Dan kewajiban Rasul itu, tidak lain hanyalah menyampaikan (agama Allah) dengan seterangterangnya (alAnkabut/29:18)

d) Bahwa Allah memerintahkan dan mencintai keadialan; menyeru kepada kemuliaan akhlaq serta mengharamkan kedzaliman, meskipun terhadap orang-orang musyrik.

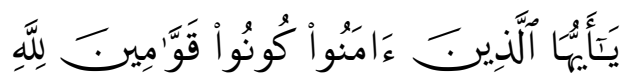

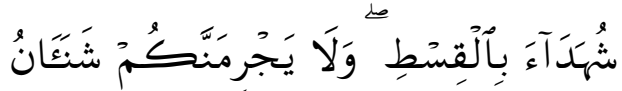

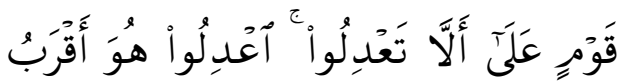
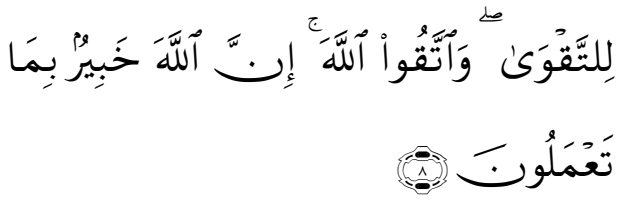

Terjemahnya:

Hai orang-orang yang beriman hendaklah kamu jadi orang-orang yang selalu menegakkan (kebenaran) karena Allah, menjadi saksi dengan adil. Dan janganlah sekali-kali kebencianmu terhadap sesuatu kaum, mendorong kamu untuk berlaku tidak adil. Berlaku adillah, karena adil itu lebih dekat kepada takwa. Dan bertakwalah kepada Allah, sesungguhnya Allah mengetahui apa yang kamu kerjakan (al-Ma'idah/5: 8)

e) Berpegang pada sikap amanah serta jujur dalam beragama; tidak saja pada ritual-ritual murni, tetapi juga dalam hal-hal yang potensial mencampur-adukkan ajaran agamaagama seperti natalan dan do'a bersama atas nama kebersamaan, kebangsaan atau kearifan lokal dan seterusnya. Toleransi tidak bermakna kesediaan mengikuti ritual dan peribadatan diluar keyakinan masing-masing umat beragama. Dengan demikian, masing-masing pemeluk agama merasa legowo dan tidak ada yang merasa tidak dihormati, apalagi 
dilecehkan, hanya karena sesama anak bangsa berpegang teguh dengan keyakinan dan keimanannya masing-masing.

f) Di luar wilayah keimanan (akidah), Islam mengajarkan tentang komitmen persaudaraan kemanusiaan (al-musawah, bukan humanism sekuler) secara adil dan penuh hikmah dalam wujud kerjasama dalam urusan-urusan dunia (mu'amalat dunyawiyah). Tanpa mencampur-aduk ajaran agama-agama. Fakta sejarah kehidupan Nabi dan masyarakat Madinah menjadi tauladan tasamuh yang sesungguhnya. Bukan seperti klaim pluralisme agama yang beriorentasi kepada penyamaan agama-agama di dunia serta menafikkan karakter yang khas pada masing-masing agama tersebut. Hal demikian, selain bertentangan dengan syariat Allah swt., juga telah mengabaikan dan menistakan hak asasi manusia untuk meyakini agamanya masingmasing.

\section{KESIMPULAN}

Sebagai kesimpulan, ada beberapa hal yang menjadi penegasan makna dari uraian tulisan ini, yakni:

1. Mengingat pemicu konflik antar umat beragama di Indonesia disebabkan oleh penodaan agama, adanya sikap mau menang sendiri serta mengabaikan kehadiran umat beragama lain, adanya diskomunikasi dan miskomunikasi. Oleh karena itu diperlukan dialog lintas agama serta pendidikan kewarganegaraan.

2. Urgensi pendidikan kewargenegaraan (civic eduaction) di Indonesia terletak pada penanaman nilai-nilai kewargaan (cicic value), yang di dalamnya terkandung upaya sosialisasi dan aktualisasi konsep, sistem, serta nilai-nilai demokrasi dan toleransi.

3. Mengingat Indonesia terdiri dari berbagai Suku, Agama dan Ras (SARA) yang tentu sangat rawan konflik, maka diperlukan proposisi untuk membina toleransi (tasamuh) sebagai 
alternatif konseptual, sekaligus sebagai landasan yang kokoh bagi kehidupan masyarakat tanpa konflik atas nama agama.

\section{DAFTAR PUSTAKA}

Azhar Basyir, Ahmad. Manusia, kebenaran Agama \& Toleransi. Yogyakarta : Perpustakaan Pusat UII,1981

Kementrian Agama RI, Al-Qur'an dan Terjemahnya. Bekasi: Penerbit Cipta Bagus Segara, 2015

Kamal, Faturahman. Implementasi Tasamuh \& Inshaf Dalam Keragaman. Manhaj Tabligh: PP.Muhammadiyah, 2016

Mustafa, Mustari. Agama Dan Bayang-Bayang Etis Syaikh Yusuf Al-Makasari. Yogyakarta; PT.LkiS Printing Cemerlang, 2011

Magnis-Suseno, Frans. Berebut Jiwa Bangsa; Dialog Perdamaian dan Persaudaraan. Cet.III; Jakarta: Kompas Media Nuasantara, 2015

Majelis Diktilitbang PP. Muhammadiyah, Pendidikan Kewarganegaraan;Menuju Kehidupan Yang Demokratis dan beradab. Cet.I; Yogyakarta: LP3 UMY, 2002

Nurhasim, Moch. Identifikasi Akar Masalah dan Solusi atas Konflik-Konflik Lokal. Litbang Pelita: Bandung, 2001
Nurhasim, Moch. Identifikasi Akar Masalah dan Solusi atas Konflik-Konflik Lokal. Litbang Pelita: Bandung, 2001

Tim Puslitbang Kehidupan Bergama.

Peta Kerukunan Umat Beragama di Propinsi Maluku, Laporan Hasil Penelitian. Bidang Litbang \& Diklat Depag Makassar , 2006 